\title{
Research on TPACK Competence of RCI Trainers
}

\author{
Yan Li \\ Tianjin Maritime College \\ Tianjin, China, 300350
}

\begin{abstract}
The integrated training model of industry and education is a new development direction in practical training, which requires trainees' comprehensive practical ability. Therefore, new requirements are put forward for professional trainers of corporations. Taking the TPACK framework as a model, this paper studied the TPACK of RCI crew training through short interviews and classroom training observation to analyze the TPACK competence of RCI trainers under the integration model of industry and education. To figure out the effective methods to train the trainers would improve TPACK of RCI trainers so that the rapid and healthy development of training in the information age could be promoted.
\end{abstract}

Keywords-RCI trainers; IT and training; TPACK; integration model of industry and education

\section{INTRODUCTION}

Tianjin Maritime College (short as TMC) has intimately cooperated with Royal Caribbean International Cruises (short as RCI) and established the only training center in China to educate the cruise talents for RCI since 2014. For the cooperation, RCI has recruited 8 Chinese trainers as its certified trainers for new hires from TMC. 8 trainers are trained annually by RCI Learning and Developing managers (short as L\&D) who are in charge of general training courses for the whole RCI fleet. Comparing the training in 2014, the training in 2019 transfer emphasis from pedagogy to TPACK (Technological Pedagogical Content Knowledge). The reason why TPACK competence takes the field for a trainer is that informatization boosts in education and Internet and $\mathrm{AI}$ products are explosive growth in the cruise industry. RCI cruises have introduced VR (Visual Reality) in dining to imitate visual sense when people taste something in their mouth. Robot bartenders travel with Quantum of the Seas and Ovation of the seas shaking amazing cocktails for guests. Excalibur which is an APP installed on smart phones to check in and check out for both guests and crew before and after the voyage. During the cruising, reservations of activities, land tours or fancy restaurants guests can make through RCI APP.

RCI training to new hires includes off-line and on-line. Off-line training is not limited to a board and pen, trainees using lap-tops and smart phones to participate class. On-line training concerns with RCI learning platform consisting of micro lessons, animation demonstrations, written materials and testing system. Off-line jointing on-line accelerates trainees' job competence. At the same time, the new crew is required both solid theory and great practical quality, so the training needs to adapt to a new integration model of production and education. "Production" means the practical skills crew need at the real workplace and "education" refers to the theoretical content in the training[1]. Due to the transformation of the training system, trainers of RCI need to be armed by TPACK to develop their career.

\section{TPACK THEORY}

Technological Pedagogical Content Knowledge (TPACK) attempts to identify the nature of knowledge required by teachers for technology integration in their teaching while addressing the complex, multifaceted and situated nature of teacher knowledge. The framework of TPACK shown in Fig. 1, explains the hear is the complex interplay of three primary forms of knowledge including content (CK), pedagogy (PK), and technology (TK). The TPACK approach goes beyond seeing these three knowledge bases in isolation. The TPACK framework goes further by emphasizing the kinds of knowledge that lie at the intersections between three primary forms: pedagogical content knowledge (PCK), technological content knowledge (TCK), technological pedagogical knowledge (TPK), and technological pedagogical content knowledge (TPACK).[1]

Content knowledge (CK) means teachers' knowledge about the subject matter to be learned or taught. As Shulman noted, this knowledge would include knowledge of concepts, theories, ideas, organizational frameworks, knowledge of evidence and proof, as well as established practices and approaches toward developing such knowledge. Koehler \& Mishra write pedagogical knowledge $(\mathrm{PK})$ is the "deep knowledge of teachers about the processes and practices or methods of teaching and learning. They encompass, among other things, overall educational purposes, values, and aims. This generic form of knowledge applies to understand how students learn, general classroom management skills, lesson planning, and student assessment.”. Knowledge about certain ways of thinking about, and working with technology, tools and resources is technology knowledge (TK). Working with technology can apply to all technology tools and resources. This includes understanding information technology broadly enough to apply it productively at work and in everyday life, being able to recognize when information technology can assist or impede the achievement of a goal, and being able continually to adapt to changes in information technology.[2]

This study was sponsored by Bofeng \& Ruihang Enterprise Management Consulting Co., Ltd. 


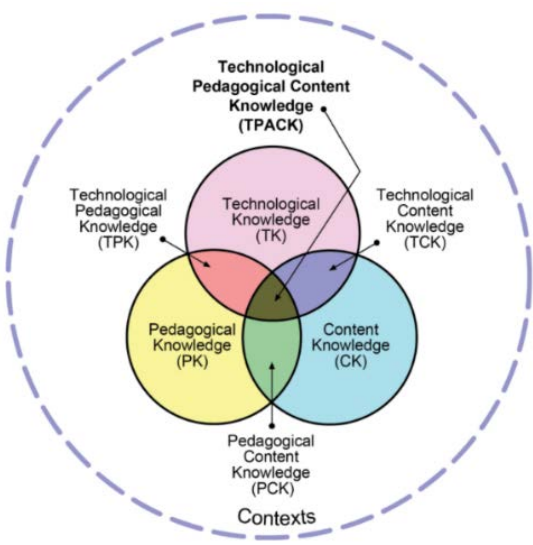

Fig.1. TPACK Framework

Consistent with and similar to Shulman's idea of knowledge of pedagogical content knowledge (PCK) is applicable to the teaching of specific content. Central to Shulman's conceptualization of PCK is the notion of the transformation of the subject matter for teaching. Specifically, this transformation occurs as the teacher interprets the subject matter, finds multiple ways to represent it and adapts and tailors the instructional materials to alternative conceptions and students’ prior knowledge.[3]

Koehler \& Mishra think that technological content knowledge (TCK) refers to an understanding of the manner in which technology and content influence and constrain one another. Teachers need to master more than the subject matter they teach; they must also have a deep understanding of the manner in which the subject matter can be changed by the application of particular technologies. Teachers need to understand which specific technologies are best suited for addressing subject-matter learning in their domains and how the content dictates or even changes the technology or vice versa.[3]

Then, technological pedagogical knowledge (TPK) is about how teaching and learning can change when particular technologies are used in particular ways. This consists of knowing the pedagogical affordances and constraints of a range of technological tools as they relate to disciplinarily and developmentally appropriate pedagogical designs and strategies.[3]

In addition, technological Pedagogical Content Knowledge (TPACK) is defined that underlying truly meaningful and deeply skilled teaching with technology. TPACK is different from knowledge of all three concepts individually. Instead, TPACK is the basis of effective teaching with technology, requiring an understanding of the representation of concepts using technologies; pedagogical techniques that use technologies in constructive ways to teach content; knowledge of what makes concepts difficult or easy to learn and how technology can help redress some of the problems that students face; knowledge of students' prior knowledge and theories of epistemology; and knowledge of how technologies can be used to build on existing knowledge to develop new epistemologies or strengthen old ones”.[4]

The above-detailed theory of TPACK is not available for teachers only, but also be able to extend in other zones such as school training, corporate training. RCI training system goes forward to adapt to the society development integrating the internet, smart devices, and artificial intelligence so that trainers of RCI are required comprehensive TPACK in their modern training. Effective technology integration for corporate training requests developing sensitivity to the dynamic, transactional relationship between these components of knowledge situated in unique contexts. Individual trainers, trainee-level, demographics, culture, and other factors make that every training class is unique which means there is no same training content, technology in different training classes.

\section{OBSERVATION}

To establish research on trainers' TPACK is necessary to understand how trainers perform in the contemporary training and finding the strength or weakness of them through it in order to find a better way to develop trainers' abilities. The research adopts case studies to collect information about the TPACK knowledge of professional trainers of RCI in the Onboarding training course and F\&B (Food and Beverage) training course in RCI Tianjin training center. We invite 8 professional trainers who are marked by T1 to T8 to participate (in TABLE I). These trainers have 4 to 10 years of training experience, age ranging from 28 to 38 . All of them are full of experience and excellent training. Onboarding course is the basic training of the history, culture, and ground rules onboard ships, while $F \& B$ course trains new hires to be qualified to serve and interact guests in F\&B department on cruises. Both courses are delivered by English, so 8 trainers own English education background or with oversea working experience. Onboarding and F\&B courses are made of theoretical and practical contents. At the same time, the training system is designed to utilize various IT (information \& technology) measures to complete the training process.

TABLE I. TRAINERS INFORMATION

\begin{tabular}{|c|c|c|c|c|c|}
\hline Trainer's NO. & Sex & Training course & Major & Degree & $\begin{array}{c}\text { Experience } \\
\text { (year) }\end{array}$ \\
\hline T1 & Female & Onboarding & Hospitality & Master & 5 \\
\hline T2 & Female & Onboarding & English & Bachelor & 5 \\
\hline T3 & Male & Onboarding & Hospitality & Diploma & 4 \\
\hline T4 & Female & F\&B & Education & Master & 8 \\
\hline T5 & Female & F\&B & English & Bachelor & 7 \\
\hline T6 & Female & F\&B & Tourism & Master & 7 \\
\hline T7 & Male & F\&B & Hospitality & Diploma & 5 \\
\hline T8 & Male & F\&B & Interpreting & Master & 10 \\
\hline
\end{tabular}


The case studies are conducted by 3 RCI L\&D managers. Interview 8 trainers in 1 day firstly. Then, they observe and evaluate the 8 trainers in every single dimension in the TPACK framework in training classrooms for 40 working days. They spend 5 days in each trainer's classroom from 9 am to 4.30pm to observe the training practice and write down the assessment of the trainer' TPACK. After one trainer's 5 days observation, they discuss the results of the performance and summarize a final comment for the trainer. Combining TPACK framework and assessment of 8 trainers, we analyze the results from 4 factors that trainers' understanding of IT and training integration, new training strategies and knowledge from IT, integration of IT resources and training, as well as instant feedback from trainees.

\section{A. Trainers' understanding of IT and training integration}

L\&D managers interview 3 questions: why should professional training integrate IT? what are the characteristics of training combining IT under the production and education integration model? what benefits does IT bring to the training under the production and education integration model?[5] The participants who are interviewed agree consistently that IT brings great progress to teaching and training. For example, the application of multimedia technology, 3D technology, and computer simulation technology can fully stimulate students' interest in learning, attract students' attention in the class and improve learning efficiency. The trainer $\mathrm{T} 2$ and $\mathrm{T} 5$ believe that the use of software, such as a cocktails' making application (APP) “Cocktails”, microlesson editing software Camtasia, a courseware editing tool Focusky, etc., can make the boring and difficult theoretical knowledge so expressive, intuitive and easy to understand that enhance students' inputs. T1 and T6 believe that practical talents should pay more attention to practical abilities in the production and education integration model, and the application of IT in training helps talents achieve practical skills. All interviewed trainers have recognized the benefits of IT are prominent in training, especially under the integration model of production and education. However, some interviewed trainers put forward their opposite opinions on how to use IT in corporate training. T8 states that the role of IT is to assist the training and the purpose of using it is to improve the training effect. Therefore, IT should not be used excessively in training. Otherwise, trainees will pay too much attention to technology, also weaken the focus on study content.

\section{B. New strategies and knowledge from IT}

The factor is about RCI trainers apply IT to support training strategy knowledge rationally and present training content knowledge. Due to trainers are so young that they have a much higher understanding and control over IT than other teachers in schools. RCI L\&D managers evaluate trainers and review that most trainers have used IT more fully and reasonably in the training process. All of them are able to use online courses to deliver lessons. TK for trainers is over-average. T7 uses animation editing software to prepare training resources to train theory part of $\mathrm{F} \& \mathrm{~B}$, transforming boring and esoteric theoretical knowledge into intuitive digital and even colorful graphics, which attracts trainees' attention and boosts their interest in learning. In meanwhile, students can remember knowledge easily and deeply through it. T3 upload the framework of the course on the internet training platform to clear the relationship between chapters, which help trainees to clear their knowledge system. PK for experienced trainers is comparatively high. Besides theoretical knowledge, practical talents must study comprehensive practical skills. Some trainers are good at English but have inadequate F\&B practical service. They have to use IT skills to cover their shortage, recording video and creating an animation to show the service standard. Trainees imitate the service video or animation to complete their training and practice on hands. Therefore, professional trainers in the model of integration of production and education need to have new training strategies and to deliver knowledge of theory and practice. However, F\&B practical skills of some trainers need to be polished because their educational background is not in hospitality. As the above observation, trainers $\mathrm{CK}$ is not as good as L\&D managers expected. Some trainers need to enhance their hands-on practice.

\section{Integration of IT resources and training}

L\&D managers assess trainers on how they use IT to express curriculum resources in training and reorganize curriculum resources. As mentioned above, trainers are so young that they can use IT measures easily. Even though some new software they never use, they can quickly hand on it. They are smart to choose the appropriate software applied in certain knowledge. T1 uses FLASH animation technology to make the structure of a cruise or interactive moves in PPT to clarify crew conduct policy. Uploading valuable resources to the training platform for trainees to learn, they drawer all resources in the right chapters. In terms of curriculum organization, the trainers utilize RCI training platform to reorganize knowledge structure and manage training resources. They do not only participate to establish the platform, but also maintain and develop it. T1 to T8 conduct quizzes on the platform during courses to collect the trainees' evaluation to improve the training. At the same time, they establish a test bank on the platform. Trainees are tested randomly by drawing test from the bank. The score is given by the test system on the platform. It proves trainers' TCK is good. L\&D managers observation shows the trainers' PCK is good as well. 8 trainers can organize the class well by activities and games. The class is positive and effective. Under the model of integration of production and education, the focus of application-oriented cultivation has shifted from the traditional theoretical foundation to the comprehensive practical abilities. The curriculum and training content has undergone major adjustments. Underlining IT measures to be used in training content, the trainers have not thought about IT cooperation with training methods. During the class, they mostly adopt traditional activities way to organize the training. Although it is fun, new technologies would impress the training better. L\&D managers notify that the trainers seldom use IT to organize the class or even smooth the class. Trainees never use software or APP to interact with their trainers except logging in training platform to read materials or finish their tests. TPK is lacking in most trainers in the model of integration of production and education.[6] Trainers are suggested to consider how to fulfill IT throughout the training to interact with trainees more. 


\section{Instant feedback from trainees}

Due to the weak TPK of trainers, they hardly use IT to monitor trainees' learning, such as how much training content trainees are able to understand or what is the obstacle for trainees to understand. Under the traditional training model in China, the training is centered on trainers. The trainers do their best to "teach" the knowledge. They always do not pay much attention to the trainees' learning. Feedback from trainees is not concerned always during the class. Few trainer exam trainees learning feedback by IT application. Therefore, the integration of IT and training feedback is the weakest in the TPACK knowledge structure of professional trainers. T3 and T6 admit in the interview that they rarely use IT to master trainees learning on daily basis. Under the training model of integration of production and education, the training transfers from the traditional trainer-centered to the trainee-centered. The trainees become the main part of training activities. Feedback from trainees would help trainers know the trainers learning so as to revise their training pace, or training content or training focus to satisfy trainees' needs. In order to make the training better, through IT measures to master trainees learning and collect trainees' comments is meaningful.

\section{RESULTS}

The results of the research show that trainers of RCI are weak in CK and TPK, so their TPACK should be improved. Then, the age of RCI trainers is positively correlated with PK. The older the age is, the higher the PK level is; and the other dimensions are not significantly related to the age. Relevant research found that the training background of trainers is positively related to TK and PK. The higher trainer's academic qualification is, the higher level of TK and PK are. However, this study illustrates that the educational background of trainers is negatively correlated with CK. That claims the English major or education major trainers are lacking in CK while the hospitality major those are good at CK. Other aspects are not significantly related to each dimension of TPACK. TK does not show an advantage among highly educated trainers. The relation is like the higher education, the smaller age, the less experienced teaching experience. The trainers with high seniority and long training experience are experienced in training, but they are not enthusiastic about continuing to pursue a degree. Although trainers graduated from linguistics or hospitality majors, they can apply basic IT well in class. Except for the need for more IT supports in higher disciplines such as AI technology or computer linguistics, the trainers can use a sort of common software to edit training content. Moreover, they rarely apply IT tools to interact with trainees in the class, which could make the interaction more effective. Consequently, their TPACK awareness is positive, but the company requires more. RCI requests its crew to master practical skills with fundamental IT. For example, crew need know the operation of pad to assist guest to order beverages in robot bar onboard. Trainers have to train their trainees to grasp some IT operation, so build up trainees' sense of IT started from IT tools used in class often.

In addition, the integration of production and education model is essential in corporate training. In order to enable the rapid integration model of production and education, trainees of RCI need to adapt to company and serve the company quickly. Trainers need to adapt to the training model of integration of production and education quickly. Therefore, vocational training to improve trainers' TPACK knowledge for the professional trainer is needed. Professional trainers vocational training is based on their knowledge of TPACK. In recent years, RCI has paid more and more attention to the quality of crew training in Tianjin training center. In order to improve the quality of training, RCI has carried out various vocational trainings for professional trainers. Previously, trainers' vocational training concerned about renewed training content, or training methods in the classroom or on ships, regardless of the TPACK framework. Research has not shown up about trainers TPACK level that can instruct the vocational training for trainers[7]. Although the current trainers' vocational training has played a certain role in improving their training level and quality, there is still an obvious gap between the RCI demand and trainers' qualification. And the actual results tell us the trainers TPACK is not satisfactory. In order to make the training model of integration of production and education can be developed quickly and healthily. Hence, we carry out this research aim to evaluate the trainers TPACK performance and design a better training plan for the trainers.

Through discussion and analysis with L\&D managers who observe 8 trainers in the classroom, we figure out the most insufficiency and weakest knowledge of TPACK of the trainers are CK and TPK. CK is the knowledge of specific practical knowledge and TPK is to glue technology with pedagogy knowledge. To improve the trainers $\mathrm{CK}$, RCI is going to arrange corporate professionals (eg. F\&B manager or supervisor) to train the trainers instead of $L \& D$ managers in training, because $\mathrm{F} \& \mathrm{~B}$ professionals have stronger practical technics and richer practical knowledge than L\&D managers. L\&D managers do not train any specific skills for operation divisions onboard. The second way to train the trainers is to send them to cruises to shadow crew in different divisions to fully master the knowledge and skills through asking and doing. A more effective measure is to "integrate" corporate professionals and professional trainers. To integrate the practical skills of corporate professionals with the theoretical knowledge and IT application ability of the trainers, we will organize some seminars to offer chances of joint study and discussion about how to integrate the curriculum resources, curriculum organization, training strategies, training characterization with IT for corporate professionals and professional trainers. Corporate professionals will consider what curriculum resources and training materials are needed to develop the practical ability of the crew. Professional trainers will consider how to organize and deliver these curriculum resources and training materials by IT and pedagogy methods. For example, in the aspect of cultivating trainees $F \& B$ service at the table, F\&B professional in RCI provides service procedures knowledge and details in service skills and the trainers use IT and training strategies to connect the knowledge and skills. When the knowledge and skills integrate perfectly by IT, they would be vivid and understandable for trainees easily. Only by integrating corporate professionals and professional trainers can we truly improve the TPACK knowledge of the trainers in the model of integration of production and education. 


\section{SUMMARY}

RCI has put "training the trainers" program as an important role in its administration since it established the only training center in Tianjin Maritime College. The society and cruise industry need the training to adapt to the integration model of production and education. With IT development, many industries education institutes start using IT in production and teaching respectively. That requests modern trainers of the corporation to possess TPACK qualification. We conduct research of RCI trainers in Tianjin training center to understand their TPACK advantages and disadvantages. The results of the investigation show us CK and TPK are comparatively low while another dimension in TPACK is relatively high for RCI trainers. Base on the results, we try to find better ways to train the trainers to improve their comprehensive TPACK ability. One is to invite corporate professionals in a different department in RCI to train the trainers about specific practical skills and knowledge on purpose. The other is to organize seminars to arrange both corporate professionals and professional trainers to discuss and analyze training resources and IT technology application to formulate the best training system under the integration model of production and education.

\section{REFERENCES}

[1] D.A. Schmidt, E. Baran, A.D. Thompson, et al. Technological Pedagogical Content Knowledge(TPACK)[J].Journal of Research on Technology in Education, vol.42 (2), pp.123-149, 2009.

[2] M.J. Koehler, \& P. Mishra. Introducing TPCK. AACTE Committee on Innovation and Technology (Ed.), The handbook of technological pedagogical content knowledge (TPCK) for educators, pp.3-29, Mahwah, NJ: Lawrence Erlbaum Associates, 2008.

[3] Mishra, P. \& Koehler. M.J. (2009). Too cool for school? No way! Using the TPACK framework: You can have your hot tools and teach with them, too. Learning \& Leading with Technology, 36(7), 14-18.

[4] M.J. Koehle, P. Mishra. What happens when teachers design educational technology? The development of technological pedagogical content knowledge[J].Journal of Educational Computing Research, vol.32, pp.131-152, 2005.

[5] A. Lv, \& Y. Chen, Study on the Teacher's TPACK at the Applied University Under the Model of Industry and Education Integration[J]. Journal of Zhejiang Wanli University, vol.32, pp.92-96, 2019.

[6] L. Archambault, K. Crippe. Examining TPACK among K-12 Online Distance Educators in the United States[J]. Contemporary Issues in Technology \& Teacher Education, vol.9(1), pp.71-88, 2009.

[7] M.L. Niess. Preparing teachers to teach science and mathematics with technology: Developing a Technology Pedagogical Content Knowledge[J]. Teaching and Teacher Education, vol.21, pp.509-523, 2005. 